\title{
ESCENAS
}

(ensayos)

\section{Resonancia del infierno en los videojuegos: relaciones intertextuales entre el poema de la Divina comedia y los videojuegos Dante's Inferno y Devil May Cry}

FIGURAS REVISTA ACADÉMICA DE INVESTIGACIÓN ISSN 2683-2917

Vol. 3, núm. 1, noviembre 2021-febrero 2022 https://doi.org/10.22201/fesa.figuras.2021.3.1

(c) (i) (): (2)

Esta obra está bajo una licencia

Creative Commons Atribución-NoComercial-

Compartirlgual 4.0 Internacional
Resonance of Hell in Video Games:

Intertextual Relations Between

the Comedy and the Video Games

Dante's Inferno and Devil May Cry

https://doi.org/10.22201/fesa.figuras.2021.3.1.183

\section{(D) Alejandro Rodríguez}

Universidad Nacional Autónoma de México

Alejandro Lozano en su texto: "Encuentros y desencuentros entre videojuegos y literatura. Jugabilidad y narrativa en The Stanley Parabole" nos dice que "el videojuego ha afianzado buena parte de su acervo cultural a través de la lectura y posterior reelaboración de numerosas fuentes literarias" (Lozano 2017, 2).
Este argumento se puede comprobar en Dante's Inferno (EA 2010) ${ }^{1}$ y en la saga Devil May Cry (Capcom 2001-presente), ${ }^{2}$ videojuegos que manejan una serie de referencias intertextuales a la magna obra de Dante Alighieri: la Comedia.

La adaptación de obras literarias no es algo ajeno en los videojuegos, desde Alice: Madness Returns (EA 2011) basado en el libro Alice's Adventures in Wonderland de Lewis Carroll, hasta La abadía del crimen (Opera Soft 1988), que retoma la novela El nombre de la rosa de

1 Página informativa: https://www.ea.com/es-mx/games/ dantes-inferno Revisado el 20 de septiembre, 2021.

2 Página informativa: https://www.devilmaycry.com/ Revisado el 20 de septiembre, 2021. 
Umberto Eco, los nuevos formatos han realizado una labor interesante al reinterpretar los clásicos.

En este ensayo revisaré dos videojuegos pertenecientes al género del hack and slash, el cual se caracteriza por su acción desenfrenada y un sistema inspirado en los juegos de rol clásico. El primero, Dante's Inferno, fue desarrollado por el estudio Visceral Games, publicado por la empresa Electronic Arts (EA) y escrito por Will Rokos. La importancia de este título radica en cómo se adaptó el pasaje del "Infierno", perteneciente a la Divina Comedia, al formato del videojuego. Por otra parte, también revisaré la saga de Devil May Cry, enfocándome particularmente en la precuela de toda la saga: Devil May Cry 3: Dante's Awakening, ${ }^{3}$ la cual fue escrita por Bingo Morihashi y Takayasu Yanagihara, y desarrollada y distribuida por Capcom. La importancia de este título radica en cómo repercute, hasta nuestros días, la visión que tuvo Alighieri del infierno, así como los elementos simbólicos que Morihashi y Yanagihara toman de la obra del italiano.

Antes de analizar estos títulos en torno a la Comedia, quisiera plantear las similitudes estructurales que existen entre los videojuegos y la literatura, pues es habitual que en ambos formatos el personaje principal se enfrente a un reto mayor pero, al mismo tiempo, lo vemos ante una serie de subtramas o pequeñas misiones que lo ayudan a crecer y avanzar.

Según el "modelo actancial" de Greimas (cfr. Greimas 1990), existen seis actantes divididos en tres ejes, el más importante es el sujeto, quien persigue siempre un objeto de deseo u objetivo. En el caso de Harry Potter y la piedra filosofal (1997) el objeto es la piedra que da título al libro, en el caso de Drácula (1897), se persigue

3 A partir de aquí y por cuestiones de practicidad, llamaré a la obra Devil May Cry 3: Dante's Awakening simplemente con sus iniciales: $D M C 3$. poder destruir al vampiro que atemoriza a la comunidad. Sin embargo, también se pueden manifestar una serie de objetos o conocimientos que pueden ayudar a los protagonistas para conseguir su objetivo final y que obtienen mediante dichas subtramas que se desarrollan a lo largo de la trama principal.

En la primera parte de la saga Harry Potter, Harry Potter y la piedra filosofal, el protagonista nunca hubiera podido entrar a la cámara final si al principio del libro no hubiera tenido que enfrentarse a su clase de hechizos y aprender el encantamiento que abre las puertas. En Drácula existe un enfrentamiento entre Lucy Westenra convertida en vampiro y el Dr. Van Helsing, dicho suceso ayuda a que este último compruebe sus teorías sobre cómo matar a uno de esos seres sobre naturales.

\section{Las pequeñas misiones le brindan}

al personaje principal herramientas

o conocimientos que le servirán después para enfrentar un reto mayor.

Muchas veces, las subtramas o pequeñas misiones pasan desapercibidos, es decir, que no son anunciados al lector. El personaje principal se enfrenta a retos que le dan conocimientos que le servirán para después afrontar el reto mayor. Y si bien podemos apoyarnos en la división capitular de las novelas, en diversas ocasiones, estas pequeñas misiones son veladas, pues de ser anunciadas entorpecerían el sentido narrativo, aun así, queda implícito que todo este conocimiento servirá al momento final de nuestra trama principal. 
En el caso de los videojuegos, que muchas veces se dividen por misiones, niveles, objetivos o subtramas, ${ }^{4}$ se vuelve explícita la obtención de un objeto o conocimiento que servirá de apoyo. Incluso, por cuestiones de jugabilidad, la obtención de este importante objeto sí es anunciada al jugador mediante apoyos musicales y hasta visuales. Es así como podemos obtener dinero, armas o algún conocimiento que enriquecerá al personaje principal para alcanzar su objetivo final.

\section{La Comedia es una candidata ideal para ser adaptada de la literatura a los videojuegos.}

En el caso de la literatura, podríamos decir que sí existen textos que nos muestran claramente las misiones o niveles que el protagonista debe cumplir y una de las obras más nítidas en este sentido sería la Comedia. Cada círculo del infierno representaría una misión o nivel que, a su vez, se divide en pecados. Cada vez que Dante atraviesa un círculo, es como si se enfrentara y venciera un pecado diferente, esto influye en la purificación que el personaje debe obtener para llegar a los niveles más altos del paraíso, el cual sería el objetivo final del poeta Alighieri. Por lo tanto, la Comedia se trata de una candidata ideal para ser adaptada de la literatura a los videojuegos.

4 Hablo de los videojuegos que contienen una estructura narrativa en su construcción y que comúnmente conocemos como juegos de "aventuras", por lo que no deben tomarse en cuenta muchos títulos deportivos o de puzle.
Comencemos con la adaptación más cercana a la obra original, que en este caso es Dante's Inferno. ${ }^{5}$ En esta reimaginación se nos presenta a un Dante guerrero, soldado de Florencia, que ha batallado en las famosas cruzadas de principios del siglo xi. Antes de volver a casa, el personaje es apuñalado por la espalda, pero se niega a morir, lo que nos lleva a nuestra primera batalla que es contra la muerte misma.

Es curioso que el llamado a la aventura se lleve a cabo de esta forma, pues en la obra original de Alighieri, el poeta muchas veces llama la atención en el infierno debido a que es un vivo que camina entre muertos. En el caso del videojuego, Dante es un hombre vivo que, aparentemente, logró vencer a la muerte.

Al regresar a casa, Dante guerrero descubre que su esposa, Beatriz, ha sido asesinada y llevada al infierno para ser consorte del demonio. Así, nuestro personaje principal se adentra al inframundo con el objetivo de rescatar el alma de su amada. A partir de aquí vemos diferentes referencias a la Comedia, por ejemplo, en las puertas del infierno nos encontramos con el poeta Virgilio, quien ha sido enviado por Beatriz para que nos guíe por nuestra travesía, al igual que en la obra original. Por otra parte, los enemigos son almas en pena que representan los diferentes niveles, como en el Purgatorio que debemos enfrentar a infantes no bautizados.
5 A partir de aquí diferenciaré a los protagonistas de cada obra, ya que todos se llaman "Dante", de la siguiente forma: "El poeta, Alighieri" para el protagonista de la Divina Comedia, "Dante guerrero" para el protagonista de Dante's Inferno y "Dante demonio" para el protagonista de $D M C$. 
A partir de aquí, el videojuego traslada los diferentes niveles del infierno de la obra original al formato del gameplay. El Dante guerrero debe enfrentar y derrotar a los guardianes de cada círculo, como al rey Minos en la entrada del segundo círculo y a Cerbero, en el tercero. Al vencerlos y terminar con estos niveles, recibirá armamento o mejoras para su equipo y así poder enfrentar a su último enemigo: Lucifer.

Lo interesante de Dante's Inferno es la reinterpretación de la trama en el personaje principal. Resulta que, antes de partir a las cruzadas, Dante guerrero hizo una promesa de fidelidad y pureza a su esposa Beatriz, pero antes de volver a casa cae en la tentación de la lujuria y la engaña. Esto provoca que intenten asesinarlo, la maldición sobre su familia y que Lucifer tome el alma de Beatriz, pues ella arrastra el pecado de su marido.

El guerrero Dante guarda similitud con el poeta Alighieri en el hecho de que ambos deben enfrentarse a cada pecado para purificar sus almas. Al final del videojuego, el personaje principal descubre que nunca pudo vencer a la muerte y que en realidad él también vaga por el inframundo, al igual que su amada. Es así como sacrifica su alma a cambio de la salvación de Beatriz, quien asciende al cielo. Aunque, a Dante guerrero se le da la oportunidad de atravesar el purgatorio para poder expiar su alma y volver a reunirse con su esposa.

Hipotéticamente, el videojuego se iba a dividir en una trilogía: Dante's Inferno, Dante's Purgatory y Dante's Heaven. ${ }^{6}$ Sin embargo, debido a que el estudio encargado del proyecto fue cerrado, se cree que los títulos

6 Dante's purgatory y Dante's heaven eran los nombres tentativos que popularmente se le ha dado a las secuelas, en realidad nunca se supo cómo se llamarían. subsecuentes se cancelaron. Aun así, me parece de sumo interés rescatar la adaptación que realizó el equipo de Visceral Games de la obra original de Alighieri, buscando hacerla más atractiva para el público en general, así como dándole una motivación más interesante al personaje principal, pero recuperando la esencia de la Comedia como son los personajes, los simbolismos y las analogías.

En el caso del modelo actancial, vemos que Dante's Inferno retoma varios aspectos de la Comedia: el sujeto de ambas obras es el respectivo Dante; si nos enfocamos en el Infierno, el objeto de deseo es purificar su alma; el ayudante sería Virgilio; el destinador sería la fe y el destanatario sería Beatriz. Es así como podemos encontrar las relaciones intextuales no sólo en la adaptación de la obra original al videojuego, sino además en su construcción estructural. Sin embargo, creo que es más enriquecedor analizar el videojuego de Devil May Cry, particularmente si hablamos la precuela de toda la saga: Devil May Cry 3: Dante's Awakening.

En este videojuego, nuestro personaje principal es Dante, hijo del rey de los demonios Sparda, y hermano gemelo de otro semi demonio: Vergil. ${ }^{7}$ Al principio de la trama, nuestro protagonista es invitado por su hermano a una torre que conecta el infierno con el cielo. Su objetivo principal es evitar que su hermano libere el poder de su progenitor y que, por lo tanto, los demonios dominen la Tierra.

Como podemos ver, en este videojuego se utilizan diversas simetrías con la obra de Alighieri, más allá de la obviedad en los nombres, podemos utilizar el "modelo actancial" para descubrir las similitudes.

7 "Vergil" es una versión anglosajona de "Virgil" o "Virgilio". 
Vergil es el oponente de Dante, pero también es su guía en esta torre que representa el infierno.

Abilio Echeverría nos menciona, en una nota a pie de página escrita para la versión poética que realizó de la Comedia para Alianza editorial, que el infierno es una especie de cono invertido (cfr. Echeverría 2013, 22), en el videojuego, este cono ha salido del inframundo en forma de torre para buscar conquistar el mundo. Podría existir una confusión con el purgatorio pues en la Divina Comedia es representado como una montaña que conecta al inframundo con el cielo, sin embargo, sabemos que, en $D M C$ 3, dicha torre es una analogía del infierno y no del purgatorio porque en ella habitan diferentes demonios como Cerbero, el famoso perro de tres cabezas que cuida la entrada y se refugia en una cámara de hielo. Recordemos que en la Divina Comedia, este ser mitológico se encuentra en el tercer círculo, el del pecado de la gula, un lugar repleto de hielo, fango y tierra. Por lo tanto, el hecho de que en el videojuego de $D M C$ lo encontremos en una cámara helada es una clara referencia a la obra de Alighieri.

Otro ser demoníaco que encontramos es el Leviatán, una serpiente gigante que si bien no es mencionada en la obra de Alighieri, sabemos que en el folclor judeo-cristiano simboliza el pecado de la ira y, en el videojuego, el lugar donde aparece este ser, también es la morada de los sub diablos que representan este pecado.

Los enemigos que aparecen en $D M C 3$ se dividen en dos categorías: los demonios, que comúnmente conocemos en la jerga del videojuego como "jefes", y los subdiablos, que son enemigos menores. Como ya se mencionó, muchos de estos personajes son traídos directamente de la Divina Comedia como son Cerbero, las harpías y las furias, aunque hay otros que son traídos de otras mitologías o folclores como Agni y Rudra, dioses védicos que representan el fuego y el viento, respectivamente, y que en el videojuego son un par de demonios que, al ser vencidos, otorgan al personaje principal un par de armas que controlan dichos elementos. Por otra parte, tenemos siete subdiablos principales y cada uno representa a los diferentes pecados capitales, el de la ira es más violento y el de la gula traga bolsas de arena con las que después te ataca.

Algo curioso de este videojuego es que, al dirigirte a la torre, te enfrentas a una representación de la muerte, al igual que en Dante's Inferno. Podríamos interpretar esto como que, para poder entrar al reino de los muertos, primero se debe vencer a la muerte misma.

Como ya dije, el videojuego de $D M C$ me parece más enriquecedor, ya que toma los elementos de la Divina Comedia y los adapta para crear su propia mitología y construir una trama con mayor libertad que el videojuego de Dante's Inferno. Por lo tanto, DMC 3 se da el lujo de explorar, de introducir personajes diferentes a los de la obra de Alighieri e, incluso, toma figuras de otras mitologías que también hablan del inframundo para crear su propia cosmovisión.

Me remito una vez más a la versión de la Divina Comedia de Alianza editorial, ahora me refiero a la introducción escrita por Carlos Alvar, pues él nos menciona que Alighieri se inspira en Aristóteles para clasificar los pecados y castigos, asimismo, complementa su visión con aportaciones de Santo Tomás y Cicerón (cfr. Alvar 2013, XXIII). Es así como, gracias al conjunto de estos hipotextos, el poeta italiano logra crear una cosmovisión que ha inspirado a diferentes artistas, como a Dalí en las artes plásticas o a los mismos Bingo Morihashi y Takayasu Yanagihara en los videojuegos.

Si revisamos el modelo actancial de Greimas, vemos que en $D M C$ 3 el objeto de deseo de Dante también es purificar su alma al momento de detener los demonios que caza; el ayudante sería Virgilio, aunque también es su opositor; el destinador serían las armas 
que utiliza, y el destinatario sería la destrucción de la torre que conecta al inframundo con el cielo. Como podemos ver, la relación intertextual de $D M C 3$ con la Comedia no es tan evidente como en el caso de Dante's Inferno y la obra de Alighieri.

La relación de DMC 3 con la Comedia es más compleja, pero podemos encontrar un enlace más claro si nos basamos en la semiósfera planteada por Lotman (cfr. Lotman 2019), que se trata de aquellos espacios abstractos donde los sistemas semióticos se construyen a partir de sus relaciones. Si partimos de este sentido, podríamos decir que la semiósfera del Infierno de la Comedia se construye con varios elementos (torre invertida, Cerbero, pecados capitales, etc.) que retoman tanto Dante's Inferno como DMC 3; este último cruza las fronteras de las semiósferas representativas de los infiernos o inframundos de otras culturas, como la Hindú.

Es así como, en términos semióticos, los elementos simbólicos que Alighieri planteó en su poema han permanecido en la producción artística hasta el punto que son tomados, juntos con otras mitologías, por los escritores de $D M C$ para crear su propia cosmogonía, pues en el modelo actancial de este videojuego, los actantes como el sujeto (Dante) o el ayudante (Virgil) son tomados de la semiósfera de la Comedia.

En conclusión, apreciamos que la obra de Dante Alighieri tiene la estructura para resonar hasta nuestros días y ser adaptada a formatos modernos como el videojuego, tanto en sus elementos simbólicos en la semiósfera, como en su construcción estructural, así como también en el modelo actancial. Al mismo tiempo y como dice Alejandro Lozano en la cita con la que abre este ensayo, los videojuegos beben en demasía de la literatura, por lo que no sólo son un formato importante de estudio, sino que además pueden servir para actualizar los textos clásicos y permitir que obras como la Comedia puedan llegar a nuevos lectores.

\section{Referencias}

Alighieri, Dante. 2013. Divina Comedia. Introducción de Carlos Alvar, versión poética y notas de Abilio Echeverría. Madrid: Alianza.

Capcom. 2015. Devil May Cry 3: Dante's Awakening. Capcom. Written by Bingo Morihashi y Takayasu Yanagihara.

Electronic Arts. 2010. Dante's Inferno. Electronic Arts. Written by Will Rokos.

Genette, Gérard. 1989. Palimpsestos. Madrid: Taurus.

Greimas, Algirdas Julius. 1987. Semántica estructural. Investigación metodológica. Madrid: Gredos.

Greimas, Algirdas Julius. 1990. Semiótica. Diccionario razonado de la teoría del lenguaje. Madrid: Gredos.

Lotman, Iuri M. 2019. La semiósfera. Lima: Fondo Editorial de la Universidad de Lima.

Lozano, Alejandro. 2017. "Encuentros y desencuentros entre videojuegos y literatura. Jugabilidad y narrativa en The Stanley Parabole." Caracteres 6, no. 1 (mayo): 34-58. 